\title{
Recovery of Visual Function after Administration of Dabigatran Etexilate
}

\author{
Carl-Ludwig Schönfeld Marie Fischer Peter Distelmaier \\ Sebastian Philipp Patrick Paquet Katharina Haller Linda Meyer \\ Herzog Carl Theodor Eye Clinic, Munich, Germany
}

\section{Key Words}

Pars plana vitrectomy - Complications, postoperative - Visual loss - Antithrombotic agents .

Dabigatran etexilate

\begin{abstract}
A 46-year-old Caucasian female underwent pars plana vitrectomy ( $p p v$ ) for retinal detachment. After the procedure, the patient could only distinguish hand movements; the condition was tentatively diagnosed as nonarteritic anterior ischemic optic neuropathy. Conventional treatment with systemic corticosteroids and acetylsalicylic acid was ineffective and yielded substantial steroid-related side effects. Additional administration of $2 \times 110 \mathrm{mg}$ dabigatran etexilate $\left(\operatorname{Pradax}{ }^{\circledR}\right.$ ), a novel direct thrombin inhibitor, resulted in a prompt and marked improvement of visual acuity, which indicated improved blood flow in the central vessels of the optic nerve. Dabigatran etexilate may provide a promising alternative for the treatment of postprocedural vision loss after ppv.

(C) 2014 S. Karger AG, Basel
\end{abstract}

\section{Introduction}

Pars plana vitrectomy (ppv) is a proven and basically safe procedure with a low incidence of complications [1,2]. However, serious adverse events can and do occur, the most serious complications being endophthalmitis [3], hemorrhages and nonarteritic anterior ischemic optic neuropathy (NAION), a potentially blinding condition [4]. An investigation in a random sample of $5 \%$ of the American Medicare beneficiaries [5] over a period of 12 years (1994-2005) yielded an incidence of approximately $7 \%$ for postprocedural blindness after ppv without an appreciable trend over time. Whereas endophthalmitis is widely considered 
Schönfeld et al.: Recovery of Visual Function after Administration of Dabigatran Etexilate

and investigated in the literature concerning post-ppv complications [1-3], the incidence of postprocedural loss of vision due to NAION appears to be somewhat underreported. Following the concept of vascular occlusion as a key factor in sudden blindness, the conventional mainstay for the treatment of postsurgical loss of vision is the systemic administration of corticosteroids and anticoagulants, e.g. acetylsalicylic acid [6-8]. However, there is no generally accepted, well-proven treatment for NAION currently [9]. In the past decade, a number of novel protein-based direct thrombin inhibitors became available for the treatment of diseases associated with undesired blood clotting. One of those agents is dabigatran etexilate, presently approved for the prophylaxis of venous thrombosis after hip or knee arthroplasty and stroke in patients with atrial fibrillation [10]. After all conventional methods of reversing the visual loss in our patient had failed, we resorted to a therapeutic trial of dabigatran etexilate, and the results are reported here.

\section{Case Presentation}

A 46-year-old Caucasian female underwent ppv of the right eye with endolaser treatment and $\mathrm{C}_{2} \mathrm{~F}_{6}$ (hexafluoroethane) gas tamponade as per the current guidelines [11] for retinal detachment. After the procedure, the vision of the treated eye was practically lost, and the patient was only able to distinguish hand movements. The retina was flat and the macula well attached (fig. 1). The afferent pupillary defect (APD) was positive, and perimetry revealed a severe loss of the visual field (fig. 2). The administration of a conventional therapeutic regimen [consisting of prednisolone $(100 \mathrm{mg} /$ day for 3 days, $80 \mathrm{mg} /$ day for 3 days, $60 \mathrm{mg} /$ day for 3 days, $40 \mathrm{mg} /$ day for 3 days, and $20 \mathrm{mg} /$ day for 3 days) and acetylsalicylic acid (100 mg)] improved visual acuity only marginally to logMAR 1,4 (fig. 3) with positive APD.

Since pronounced corticosteroid side effects (sleeplessness, facial edema, restlessness, sweating and tachycardia) burdened the patient and the treatment showed practically no effect, we decided to try to improve her vision with the administration of dabigatran etexilate $(2 \times 110 \mathrm{mg})$, a novel direct thrombin inhibitor, 24 days after the initiation of the prednisolone/acetylsalicylic acid treatment. Promptly after the first administration, visual acuity improved to $\log$ MAR 1,0 and continued to improve to logMAR 0,4 (fig. 3). APD was still positive. Perimetry done 26 days afterwards showed a marked improvement in central sensitivity from 7 to 25 and $21 \mathrm{~dB}$, respectively; the nasal part of the visual field also showed an increase in sensitivity (fig. 4), and APD was negative.

\section{Discussion}

Strictly speaking, the diagnosis of NAION requires the exclusion of arteritic alterations, usually by temporal artery biopsy. However, a sudden loss of vision after ocular surgery without signs of retinal detachment or other intraocular alterations strongly suggest ischemic neuropathy, and tentative diagnosis and treatment are warranted [4]. Since NAION is not a disease as such but rather the common endpoint of a large number of local and systemic conditions, there is no established standard therapy [9]. However, systemic corticosteroids in combination with anticoagulation to reduce swelling and improve venous blood flow are basically accepted modalities. When this approach failed in the present case, we resorted to the off-label administration of a novel direct thrombin inhibitor, resulting in a dramatic recovery of visual function. 
Schönfeld et al.: Recovery of Visual Function after Administration of Dabigatran Etexilate

It would be premature to construe this as a direct medication effect, though. NAION is known to show spontaneous remission in approximately $40 \%$ of the cases [4], but this assumption notwithstanding, improvement of blood flow is an accepted measure whose indication to preserve or restore vision is undisputed. Therefore, the striking improvement of vision after the administration of dabigatran etexilate in the present case may warrant a systematic clinical trial of a combination of corticosteroids and dabigatran etexilate in comparison with (for instance) warfarin as is common practice under different indications for anticoagulation [12-14]. However, when ophthalmologists consider the administration of dabigatran etexilate for NAION, certain peculiarities and disadvantages of the drug (such as the lack of an antidote $[12,15]$ ) need to be borne in mind to avoid potential hazards.

\section{Acknowledgment}

This case report was supported by a grant from the Foundation of the Herzog Carl Theodor Eye Clinic, Munich, Germany.

\section{Disclosure Statement}

The authors have no conflicts of interest to declare.

\section{References}

$\checkmark 1$ Gupta OP, Weichel ED, Regillo CD, et al: Postoperative complications associated with 25-gauge pars plana vitrectomy. Ophthalmic Surg Lasers Imaging 2007;38:270-275.

-2 Parolini B, Prigione G, Romanelli F, Cereda MG, Sartore M, Pertile G: Postoperative complications and intraocular pressure in 943 consecutive cases of 23-gauge transconjunctival pars plana vitrectomy with 1 year follow-up. Retina 2010;30:107-111.

3 Maalouf F, Abdulaal M, Hamam RN: Chronic postoperative endophthalmitis: a review of clinical characteristics, microbiology, treatment strategies, and outcomes. Int J Inflam 2012;2012:313248.

-4 Egan R, Rizzo JF 3rd: Neuroophthalmological complications of ocular surgery. Int Ophthalmol Clin 2000;40:93-105.

-5 Stein JD, Zacks DN, Grossman D, Grabe H, Johnson MW, Sloan FA: Adverse events after pars plana vitrectomy among Medicare beneficiaries. Arch Ophthalmol 2009;127:1656-1663.

6 Hayreh SS: Ischemic optic neuropathy. Prog Retin Eye Res 2009;28:34-62.

7 Hayreh SS, Zimmerman MB: Non-arteritic anterior ischemic optic neuropathy: role of systemic corticosteroid therapy. Graefes Arch Clin Exp Ophthalmol 2008;246:1029-1046.

-8 Unsöld R: Anterior ischemic optic neuropathy: etiology, pathogenetic mechanisms and therapy (in German). Ophthalmologe 2008;105:867-882.

-9 Atkins EJ: Nonarteritic anterior ischemic optic neuropathy. Curr Treat Options Neurol 2011;13:92-100.

10 Ahrens I, Peter K, Lip GY, Bode C: Development and clinical applications of novel oral anticoagulants. Part I. Clinically approved drugs. Discov Med 2012;13:433-443.

-11 Schwartz SG, Flynn HW Jr, Lee WH, Ssemanda E, Ervin AM: Tamponade in surgery for retinal detachment associated with proliferative vitreoretinopathy. Cochrane Database Syst Rev 2009;7:CD006126.

$\checkmark 12$ Altman R, Vidal HO: Battle of oral anticoagulants in the field of atrial fibrillation scrutinized from a clinical practice (the real world) perspective. Thromb J 2011;9:12.

$\$ 13$ Lucà F, La Meir M, Rao CM, et al: Pharmacological management of atrial fibrillation: one, none, one hundred thousand. Cardiol Res Pract 2011;2011:874802.

14 Pink J, Lane S, Pirmohamed M, Hughes DA: Dabigatran etexilate versus warfarin in management of nonvalvular atrial fibrillation in UK context: quantitative benefit-harm and economic analyses. BMJ 2011;343:d6333.

15 Reddy P, Atay JK, Selbovitz LG, et al: Dabigatran: a review of clinical and pharmacoeconomic evidence. Crit Pathw Cardiol 2011;10:117-127. 
Case Reports in

Ophthalmology

\begin{tabular}{l|l}
\hline Case Rep Ophthalmol 2014;5:262-266 \\
\hline DOI: $10.1159 / 000365961$ & $\begin{array}{l}\text { C 2014 S. Karger AG, Basel } \\
\text { www.karger.com/cop }\end{array}$ \\
\hline
\end{tabular}

Schönfeld et al.: Recovery of Visual Function after Administration of Dabigatran Etexilate

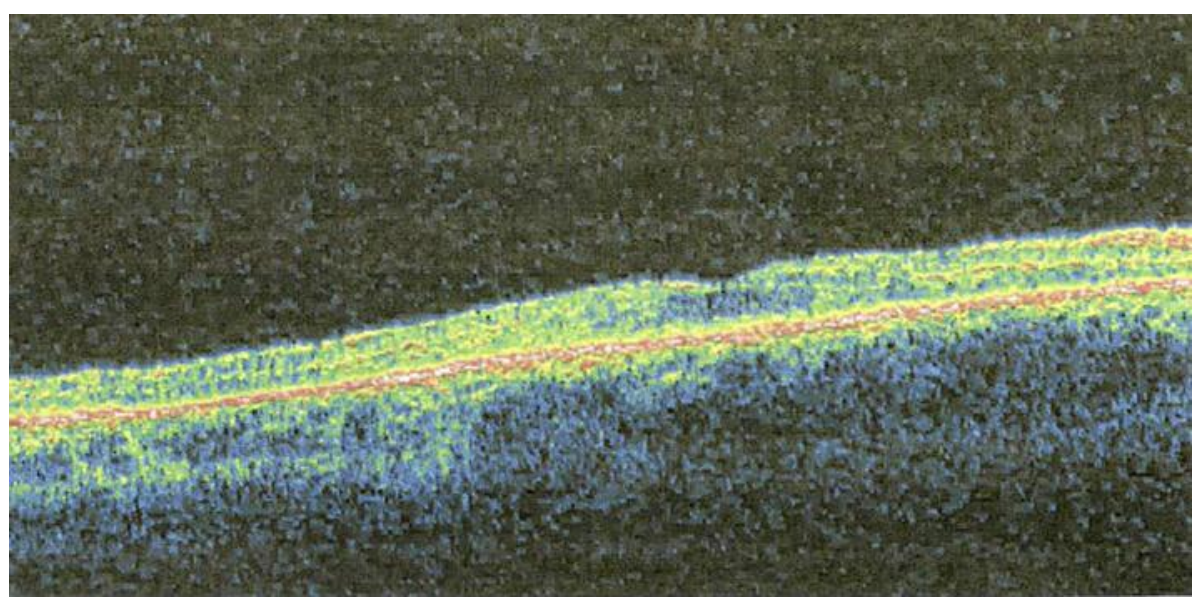

Fig. 1. Optical coherence tomography 19 days postoperatively.
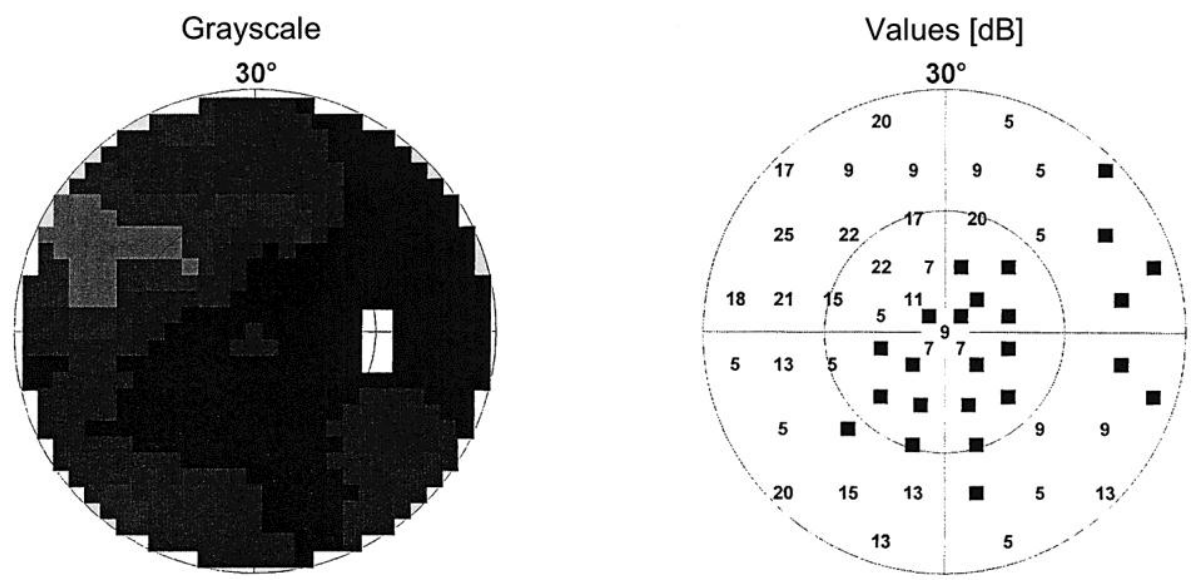

Fig. 2. Visual field before the administration of dabigatran etexilate (Octopus 101; Haag-Streit Deutschland GmbH, Wedel, Germany). Duration 4 min 53 s, 132 targets, ambient luminance 4 Asb. 
Schönfeld et al.: Recovery of Visual Function after Administration of Dabigatran Etexilate

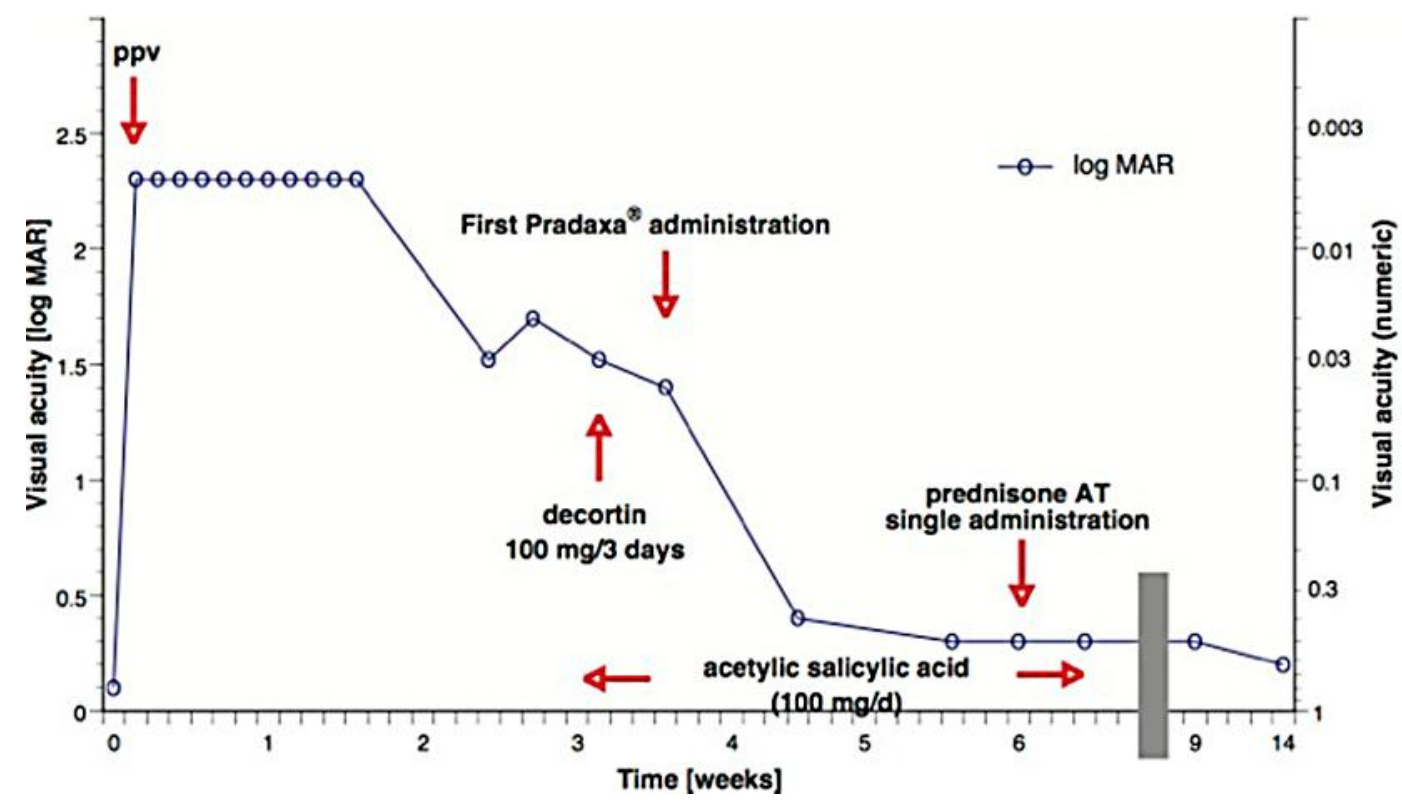

Fig. 3. Development of visual acuity over time.
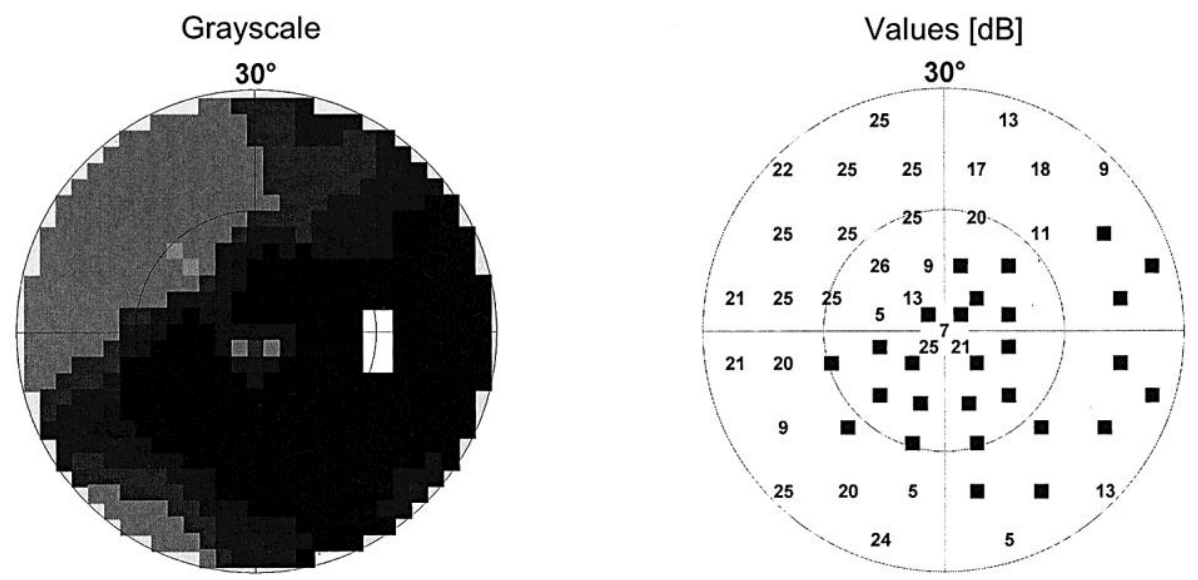

Fig. 4. Visual field after the administration of dabigatran etexilate [duration 5 min $52 \mathrm{~s}, 144$ targets, ambient luminance $4 \mathrm{Asb}$ (for examination parameters, see text)]. 